NOTAS

JORGE IBARGÜENGOITIA A 20 AÑOS DE SU MUERTE

Jaime Castañeda*

No es humor aquello que hace reír y produce enajenación: el verdadero humorista hace de la risa un despertar de la conciencia.

Sören Kierkegaard

Mi manera de bromear es decir la verdad; es la mejor chanza del mundo.

Bernard Shaw

Conocí a Jorge Ibargüengoitia a través de sus artículos en la página editorial de Excélsior. La primera reacción ante esos artículos era siempre soltar la carcajada; pero luego, por supuesto, venía la reflexión, porque no se trataba solamente de hacer reír, sino de desnudar la realidad, de trivializar en anécdotas aparentemente absurdas lo trascendente, de poner en evidencia una serie de cuestiones significativas, de 'decir' además de

* Departamento Académico de Estudios Generales, ITAM; Dirección de Humanística, Universidad Marista. contar, y finalmente -como expresó José de la Colina- de penetrar en el desilusionante pero a la vez divertido juego del mundo, ridiculizando la solemnidad de nuestra vida diaria.

El mismo desenfado y naturalidad para contar que se reflejaba en su columna de Excélsior, lo encontré posteriormente en sus novelas. Las únicas en la literatura mexicana contemporánea que logran mostrarnos la otra cara-quizá la auténtica- de nuestra realidad actual y pretérita. Las únicas que se atreven a desacralizar a los héroes nacionales, despojándolos del oropel y describiéndolos de 
NOTAS

carne y hueso, con sus virtudes y defectos. No hay duda de que en las obras de Ibargüengoitia existe el propósito crítico, sin embargo, predomina en ellas el espíritu lúdico: ese juego del mundo, juego de los seres y de las cosas, de la Gran historia y de la pequeña historia, que conforman el Gran teatro del mundo; siempre bajo esa doble perspectiva desmitificadora y humorística que le confiere un carácter tan singular.

Tiempo después conocí al escritor guanajuatense personalmente. Lo primero que uno advertía en él era su corpulencia física, o dicho de otra manera, su gordura. Característica que correspondía a la imagen de cierto tipo de humoristas como Chesterton, Oscar Wilde o Gómez de la Serna, por mencionar a tres de los más representativos. Otro tipo sería el que se identifica con la imagen -física e intelectual- de un Bernard Shaw, vegetariano, asceta e invariablemente malhumorado (tal vez por falta de proteínas).

Posteriormente, visité a Ibargüengoitia varias veces en su casa de Coyoacán.* Aquellas visitas me revelaron que el novelista mostraba y demostraba insistente buen humor: era

* En un principio dichas visitas-entrevistas obedecieron a que por aquella época trabajaba en mi tesis de licenciatura, titulada: El humorismo desmitificador en la narrativa de Jorge Ibargüengoitia. un hombre sencillo, antisolemne que expresaba lo que sentía sin rodeos. Hablaba como escribía, escribía como hablaba, y en todo era espontáneo, pausado, gesticulador. Eso sí, detrás de esos ojos saltones con párpados a media asta, qué lúcido y sincero, qué irónico y campechano era.

Aunque siempre detestó 'la pinche etiquetita ésa de humorista’, esta cualidad lo convierte en la excepción que confirma la regla de nuestra literatura nacional, donde no es nada frecuente el tono humorístico, ni el sentido del humor.

Efectivamente, Ibargüengoitia es un autor singular; donde todos respetan y veneran la Revolución mexicana, él escribe un libro en el que caricaturiza, parodia otros libros y ofrece el relato más creíble de un trágico episodio histórico; donde todos publican novelas de grave denuncia sobre las dictaduras que ha padecido América Latina, él concibe una deliciosa farsa, en la que los héroes son tan ridículos como sus enemigos; en un medio donde se venera tanto el 'yoísmo', Ibargüengoitia escribe un libro en el que continuamente se burla de sí mismo, y se retrata torpe, tonto, pobre, antiintelectual; donde cualquiera hubiera hecho una novela sociologizante, o una pésima novela policíaca, él presenta el divertido espectáculo de dos criminales que no entienden que lo que hacen es crimi- 
nal; y finalmente, en lugar de sublimar a los héroes de la Independencia de México, los baja de su pedestal sin armar demasiado escándalo, pero sí soltando la frase oportuna como quien no quiere la cosa; nos cuenta el episodio más importante de nuestra historia en la forma más espontánea, amena y antisolemne.

Ibargüengoitia, pues, constituye un caso insólito en la literatura mexicana. Hoy lo recordamos con gran nostalgia, a veinte años de su muerte (noviembre de 1983).

\section{El escritor}

Jorge Ibargüengoitia nació en Guanajuato en 1928, pero emigró con su familia a la ciudad de México apenas cumplidos los tres años. Realizó sus primeros estudios en diferentes escuelas particulares hasta terminar la preparatoria en el Colegio Francés Morelos, de los maristas, hoy Centro Universitario México, CUM.

Respecto a su vocación literaria el propio Ibargüengoitia decía: “A los diez años hice un periódico; no sé que tenía adentro ni sé que escribí, pero toda la gente que veía ese papel, se daba cuenta de que era un periódico. Después escribí algunos cuentos, pero desde los doce años sufrí una especie de bloqueo y durante los siguientes diez años no escribí y casi

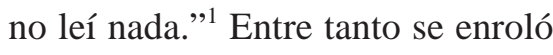
con los boys scouts, donde pasó los mejores años de su adolescencia.

Obligado por las circunstancias y como toda persona inclinada hacia las artes, realizó sus primeros estudios superiores en la escuela equivocada, en su caso de ingeniería de la UNAM. El equívoco se prolongó de 1945 a 1948, año este último en que viajó a Europa. A su regreso, un año después, todo cambió. Terminar la carrera de Ingeniería le pareció una pérdida de tiempo por lo que la abandonó y se fue a trabajar a un rancho que su familia tenía en Guanajuato. Allí estuvo tres años.

En un artículo que publicó en 1974, Ibargüengoitia cuenta cómo nació en él su vocación literaria. Todo empezó porque estando en el rancho un motor diesel se descompuso, lo que le obligó a viajar a la ciudad de Guanajuato para repararlo. Al llegar a la casa de su madre se encontró que estaba de visita un señor que él no conocía y que estaba en Guanajuato para presentar una obra de teatro de la cual era director. Se trataba de la obra Rosalba y los llaveros de Emilio Carballido. El señor era nada menos que Salvador Novo, quien in-

\footnotetext{
${ }^{1}$ Margarita García Flores, "Entrevista a Ibargüengoitia”, Cartas marcadas, 1979, México, Textos de Humanidades, UNAM, p. 187.
} 
NOTAS

vitó al joven ‘ingeniero’ al estreno, esa misma noche en el Teatro Juárez.

No sé si la representación fue excelente o si mi condición anímica era extraordinariamente receptiva. El caso es que ahora sé, y confieso con un poco de vergüenza, que ninguna representación teatral me ha afectado tanto como aquella Rosalba y los llaveros que yo vi en el Teatro Juárez. Es posible que si el motor diesel no se hubiera descompuesto otra vez el lunes siguiente, yo hubiera tenido tiempo de regar el trigo, hubiera seguido en el rancho y ahora sería agricultor y, ¿por qué no?, millonario. Pero el motor diesel se descompuso el lunes, yo dije: ¡basta de rancho!, y en ese instante dejé de ser agricultor. Tres meses después me inscribí en la Facultad de Filosofía y Letras. ${ }^{2}$

Cuatro años después de haber ingresado a la Facultad obtuvo su título de maestro en Literatura, especializado en Arte dramático. Su orientación hacia el teatro es fácilmente explicable; por aquel entonces Rodolfo Usigli impartía en la Facultad el único curso donde se 'enseña-

2 Jorge Ibargüengoitia, “Otras voces, otros teatros. La vida en México en tiempos de Novo”, Excélsior, 18 de Febrero de 1974. ba’ el arte de escribir: Teoría de composición dramática.

Sin lugar a dudas, la influencia de Usigli fue decisiva en los años de formación de Ibargüengoitia. Por otro lado, el guanajuatense fue el alumno preferido del famoso dramaturgo, prueba de ello es el apoyo que siempre le brindó. Mas esto, no fue nada gratuito, obviamente obedeció a que Usigli vio en Ibargüengoitia un gran talento que seguramente sus demás alumnos no tenían. El reconocimiento a la capacidad literaria de Ibargüengoitia, así como la predilección que Usigli le tenía, quedan manifiestos en varias cartas publicadas por Vicente Leñero, en una serie de artículos que aparecieron en la revista Siempre! bajo el título "Los pasos de Jorge" 3 publicadas en agosto y septiembre de 1987.

Por su parte Ibargüengoitia reconoció siempre la influencia y el apoyo de su maestro:

Rodolfo Usigli fue mi maestro, a él debo en parte ser escritor y por su culpa, en parte, fui escritor de teatro diez años. Digo que fue mi maestro en el sentido más llano de la palabra: él se sentaba en una silla y daba clase y yo me sentaba en otra y le oía, haciendo de vez en cuando algún apunte en mi libre-

${ }^{3}$ Nos. 1783 y 1784, 26 de Agosto y 2 de Septiembre de 1987. 
ta -cosas como 'Farquhar no respeta las unidades', etc.-. Esto ocurrió durante dos horas de dos tardes cada semana de los tres años que seguí en su curso en Filosofía y Letras. Sin la clase de Usigli mis estudios en esa institución hubieran sido completamente banales y probablemente no me hubiera tomado el trabajo de terminarla. ${ }^{4}$

En relación a su época de dramaturgo, el propio Ibargüengoitia escribió un artículo en la Revista de la Universidad de México, en el cual, con su característico humor, relata estos años de su vida:

Cuando llegué al umbral de la carrera de las letras, tenía yo veintitrés años, setenta mil pesos en documentos y una experiencia de más o menos lo siguiente: Había estudiado hasta cuarto de ingeniería y lo había reprobado por completo; había trabajado de topógrafo, de laboratorista de mecánica de suelos, de calculista de lo mismo y de dibujante; había sembrado jitomate con un éxito arrollador, lechugas, maíz y frijol (sin éxito el frijol); y sabía cómo limpiar una noria e instalar una bomba.

${ }^{4}$ Jorge Ibargüengoitia, "Recuerdo de Rodolfo Usigli”, Revista Vuelta, n³3, agosto de 1979.
Ahora bien, como ninguna de estas actividades es de utilidad para un escritor, vivía yo de los setenta mil pesos. En 1953 compré un terreno en Coyoacán, y desde ese momento se acabó mi vida de rentista. Estaba yo a la aventura. Era diciembre, había ya terminado mis estudios para Maestro de Letras, especializado en Arte Dramático sin pena ni gloria, y lo primero que se me ocurrió fue presentarme en la Universidad Iberoamericana a pedir unas clases. Me las dieron inmediatamente y de Doctorado. Durante la primera parte de 1954 viví de los $\$ 480$ que me pagaban por mis clases y los $\$ 100$ que me daban a veces en la UNAM por sustituir a Usigli; luego en septiembre, me gané la beca del Centro Mexicano de Escritores y montaron Susana y los jóvenes, que me produjo mil pesos de derechos. En esa época pagaba yo cincuenta pesos de renta, así que con los mil o mil quinientos pesos que hacía cada mes, podía vivir en la opulencia. Así pasó un año. En 1955, me becó la Rockefeller en Nueva York, brindándome de esa manera, no sólo la oportunidad de ver otras tierras, sino de poder comprarme camisas cada vez que me diera la gana. Cuando regresé de los Estados Unidos, me encontré con que el Centro Mexicano de Escritores 
NOTAS

estaba tan satisfecho con mi actuación que había decidido concederme otra beca. Aquí fue cuando empezó mi neurosis. Se me ocurrió hacer un poco de ascetismo. Dejé mis clases y otras actividades y me reduje a vivir con la beca del Centro... ${ }^{5}$

Independientemente de las obras que escribió siendo aún estudiante (Cacahuates japoneses y Llegó Margot, ambas inéditas), la actividad profesional de Jorge Ibargüengoitia empezó a ser aplaudida en 1954 con el estreno de Susana y los jóvenes, publicada un año después en una antología de la Editorial Aguilar de Madrid. Asimismo, su obra Clotilde en su casa -estrenada en 1955 en el Teatro Rotonda bajo el título Adulterio esquisito-, fue incluida en el tercer tomo del Teatro mexicano contemporáneo, que al año siguiente publicó el Fondo de Cultura Económica. Estas dos obras, más Ante varias esfinges que escribió en 1956, lo convirtieron en uno de los mejores dramaturgos jóvenes de aquella época.

De esa misma época son La Lucha con el ángel, que aunque nunca se estrenó obtuvo una mención en el

${ }^{5}$ Jorge Ibargüengoitia, “¿De qué viven los escritores?”, Revista de la Universidad de México, $\mathrm{n}^{\circ}$ 4, vol. XVII, diciembre de 1962. concurso de Teatro latinoamericano de Buenos Aires, en 1956. Poco éxito tuvieron, en cambio, El loco amor viene, El tesoro perdido y Dos crímenes, piezas en un sólo acto que escribió en 1957 y que jamás se estrenaron, no obstante que la primera de ellas ganara un concurso de teatro organizado por el Ateneo Español en México.

Dos años después, esto es en 1959, Ibargüengoitia escribió dos comedias que tampoco se representaron, al menos en forma profesional, El viaje superficial y Pájaro en mano. No fue hasta 1964 que fueron publicadas por la Universidad Veracruzana, junto con Clotilde en su casa, en un libro titulado Clotilde, El viaje y El pájaro.

En 1960, Ibargüengoitia incursiona en el teatro infantil con la obra La fuga de Nicanor, estrenada ese mismo año en el teatro del Recreo infantil del Bosque, en Chapultepec. En realidad no era un género del todo desconocido para el guanajuatense; en 1956 ya había escrito una obra para niños titulada El peluquero del rey, que fue representada en varias ocasiones por el Teatro popular.

Ese mismo año escribió una comedia musical que no dio a conocer sino mucho tiempo después. Esto ocurrió en 1979, cuando ya estaba totalmente alejado del quehacer dramático y la Compañía Nacional de Teatro le soli- 
citó una obra. Jorge Ibargüengoitia se acordó entonces de esta comedia y la entregó. Finalmente, con la colaboración de Alicia Urreta que compuso la música y añadió algunas canciones, se estrenó Los buenos manejos en 1980.

Posteriormente vendría El atentado, excelente farsa histórica basada en el asesinato del general Álvaro Obregón, que obtuvo, en 1963 el premio en el Concurso de Teatro Casa de las Américas de Cuba. Un año después fue publicada por la Revista Mexicana de Literatura; sin embargo, por razones de censura no fue estrenada en México sino hasta 1975. En relación con esta obra el propio Ibargüengoitia escribió:

El atentado me dejó dos beneficios: me cerró las puertas del teatro y me abrió las de la novela. Al documentarme para escribir esta obra encontré un material que me hizo concebir la idea de escribir una novela sobre la última parte de la Revolución mexicana... ${ }^{6}$

Poco antes de que apareciera $E l$ atentado, Ibargüengoitia escribió $L a$ conspiración vendida, pieza igualmente histórica, que se debe a un encargo del Departamento de Teatro del Bellas Artes hacia finales de 1959.

6 “Jorge Ibargüengoitia dice de sí mismo”, Vuelta, n 100, marzo de 1985.
No obstante haber sido escrita por encargo no se representó, y su publicación ocurrió quince años después, en el volumen misceláneo Sálvese quien pueda, editado por Novaro en 1975. Más tarde el tema de esta obra -el inicio de la guerra de Independencia- sería ampliado en su novela Los pasos de López.

Respecto al origen de esta obra su propio autor nos refiere:

Esto empieza en octubre o noviembre de 1959. Yo estaba en una de las temporadas más desesperantes de mi vida profesional. Como escritor dramático... era entre desconocido y olvidado, tenía cuatro obras sin estrenar, no tenía ingresos de ninguna especie, deudas que entonces parecían enormes, y urgencia de pagar aunque fuera réditos vencidos. Estas circunstancias me llevaron a dar un paso que ahora me parece inexplicable: se me ocurrió ir al Departamento de Teatro de Bellas Artes a pedirles dos o tres mil pesos como anticipo sobre regalías futuras. El resultado fue que me encargaron una obra sobre algún episodio de la guerra de Independencia; presenté La conspiración vendida pero jamás se representó y sólo me pagaron la mitad de lo prometido (cinco mil pesos).... 
NOTAS

Sin embargo, el destino me deparó una venganza sensacional. En septiembre apareció una convocatoria para un concurso de obras de teatro organizado por el Departamento del Distrito Federal. Premio Ciudad de México, se llamaba. El monto del premio era de veinticinco mil pesos de entonces, que serían como diez veces eso ahora. Mandé La conspiración vendida con el seudónimo 'Federico Barón Gropius', y gané el premio. El mismo día que supe la noticia encontré a Gorostiza (Celestino), que había presidido el jurado que me premió, en el foyer de un teatro. -Yo soy el autor de La conspiración vendida -le dije. Casi se desmayó. Evidentemente habían premiado la obra creyendo que había sido escrita por otra persona con más méritos o mayores influencias que yo. $\mathrm{Ni}$ modo. ${ }^{7}$

Hasta aquí su principal labor teatral (ocasionalmente escribió pequeños diálogos escenificables y guiones cinematográficos). Como articulista (crítico, editorialista, etc.) figuró en varias de las mejores publicaciones del país; de 1960 a 1963 en la Revista de la Universidad de México, de

${ }^{7}$ Jorge Ibargüengoitia, "Dos aventuras de la dramaturgia subvencionada”, Vuelta, $\mathrm{n}^{\circ} 27$, febrero de 1979.
1962 a 1963 en el Suplemento Cultural de Siempre!, igualmente en Diálogos, la página editorial de Excélsior (de 1968 a 1976) y en las desaparecidas Snob y Revista Mexicana de Literatura. Desde la aparición de la revista Vuelta (1977), que dirigía Octavio Paz, colaboró casi invariablemente en cada número y fungió como miembro del Consejo de redacción, hasta poco antes de su trágico fallecimiento.

Fue sin embargo en la narrativa (novela y cuento) donde Ibargüengoitia alcanzó sus mayores éxitos, a partir de su primera novela Los relámpagos de agosto (1964); si bien es cierto que su farsa histórica $E l$ atentado (1962) ya había obtenido el premio de teatro de la Casa de las Américas. También hay que recordar que antes de publicar Los relámpagos de agosto, Ibargüengoitia ya era bastante conocido gracias a sus artículos de crítica teatral.

Después de la aparición de Los relámpagos -igualmente premiada por la Casa de las Américas de Cubapublicó en 1967 la colección de cuentos titulada La ley de Herodes, crónicas minuciosas de la vida capitalina, con una buena dosis autobiográfica. Dos años más tarde, en 1969, apareció su segunda novela, Maten al león, obra de gran ironía, en la que se retrata la figura del dictador patriarcal latinoamericano. 
Varias de sus experiencias en el extranjero, como becario, como artist in residence de la Universidad de Stanford, y una serie de artículos periodísticos fueron recopilados en el volumen misceláneo Viajes en la América ignota, que se publicó en 1972.

Su siguiente novela fue Estas ruinas que ves (1975), quizá menos ambiciosa que las anteriores, pero extraordinariamente divertida y que lo devuelve plenamente a la autobiografía y al intimismo de sus cuentos. Con esta obra Ibargüengoitia ganó el Premio Internacional de Novela México.

El mismo año de 1975 publicó el libro Sálvese quien pueda, en el que incluye una serie de artículos que originalmente aparecieron en Excélsior, y la obra de teatro La conspiración vendida, escrita en 1960 como señalamos. Apareció este libro mientras preparaba su siguiente novela, Las muertas, que tras muchas correcciones, se publicó finalmente dos años después, es decir en 1977. El proyecto de esta novela se remonta a mucho tiempo atrás; ya en Estas ruinas que ves se mencionaba el caso policíaco de las tratantes de blancas que a fines de los cincuenta operaron en el Bajío y recibieron el apodo de las Poquianchis, y que literalmente Ibargüengoitia bautizó como las hermanas Baladro. Las muertas es quizá la novela más completa del guanajuatense, por su hechura y complejidad; aunque sin dejar de ser la novela de un humorista, es la más seria de sus obras.

La imaginación y el bien dosificado humor de Jorge Ibargüengoitia de nuevo se hacen patentes en su quinta novela: Dos crímenes (1979), verdadero deleite donde la función narrativa se da con una naturalidad y una fluidez deslumbrantes. De tema policíaco, es desde luego la intriga lo que domina en la estructura de esta obra. Dos crímenes es uno de los mejores libros de Ibargüengoitia, que muestra la madurez y maestría alcanzadas como escritor.

La última novela de Jorge Ibargüengoitia -Los pasos de Lópezapareció en 1982; en ella nuevamente resalta la capacidad desmitificadora de su autor, esa intención satírica de desnudar la realidad, de cotidianizar la historia, la Gran historia (en este caso la historia de la Independencia nacional). En Los pasos de López, como hiciera en su primera novela, lo que intenta Ibargüengoitia con gran éxito es "delatar a la historia como la esfinge sin secreto, como pedestal vacío o desproporcionado; pero sin rencor, sin odio....", ${ }^{8}$ con ese

8 José de la Colina, “Jorge Ibargüengoitia (1928-1983), El Semanario Cultural, Novedades, de diciembre 4 de 1983. 
NOTAS

espíritu lúdico exclusivo de los auténticos escritores humoristas.

Al revisar la obra narrativa de Ibargüengoitia, observamos que muy pocos novelistas han escrito economizando tanto la literatura como él, y esto nos parece no un defecto sino una virtud. Es decir, en estos casi veinte años de producción, seguramente por su perspectiva humorística y desmitificadora, no ha caído, afortunadamente, en el superado análisis sociologizante tan común en nuestros novelistas. Su mérito principal ha encontrado fuerza en un bisturí; las historias que narra han sido extraídas de la vida misma, la del pueblo mexicano, a manera de un cronista. Tampoco existen las densidades sicológicas, los símiles sorprendentes o las deslumbrantes metáforas. Mas esto no quiere decir que no haya habido una progresión y una maduración del autor en el arte de narrar y de contar, al contrario, supone mucho oficio lograr la perfecta sencillez, la naturalidad del verdadero artista.

Ahora bien, la crítica constantemente deja en el tintero el considerar ese sentido del humor desmitificador propio de Ibargüengoitia determinado por sensaciones y concepciones mucho más profundas que la mera humoricidad que hace reír al lector. Hay un fluir de cosas que no van subrayadas pero que nos llevan a la reflexión. Decía Kierkergaard que no es humor aquello que hace reír y produce enajenación; que el verdadero humorista debe hacer de la risa un despertar de la conciencia. Creo que es el caso de Jorge Ibargüengoitia.

Otro de los rasgos distintivos que concurren en la obra del guanajuatense es, sin duda, su fecunda imaginación, elemento indispensable de toda obra literaria. Ibargüengoitia es uno de nuestros escritores más creativos e ingeniosos, no tanto por los temas que elige, los personajes que caracteriza o los ambientes que recrea sino, especialmente, debido al manejo argumental o tratamiento que da a sus historias, al tono que utiliza para narrar y, en suma, a la perspectiva desde la cual mira la realidad que nos describe.

Ibargüengoitia, sin embargo, es un escritor que hasta ahora no ha sido valorado en toda su capacidad, pues siempre se le ha ensalzado la virtud de hacer reír al lector, olvidándose casi por completo de sus demás cualidades literarias; ha vivido la injusticia de ser minimizado como novelista por 'chistoso', como si humorista y cómico fueran los mismo o como si el humor no fuera importante en la vida.

\section{El humorista}

Preciarse de tener sentido del humor ha llegado a considerarse como algo 
importante en nuestra sociedad. Todo el mundo presume de tener ese 'don', lo que no suelen especificar es si tienen sentido del buen humor o del mal humor, o si tienen, sencillamente, un erróneo sentido del humor. Si a alguien se le dice que su humor es muy bueno, habremos expresado un cumplido; pero si se le dice lo contrario, se sentirá insultado.

Sigmund Freud distingue a las personas capacitadas para el humor y afirma que éste "no se halla a disposición de todo el mundo y, ampliamente, sólo a la de contadas personas a las que caracterizamos diciendo que tienen gracia”. ${ }^{9}$ Es decir, es una cualidad de ciertas personas -no muchas-. Para Ramón Gómez de la Serna el humorismo es una condición de superioridad.

Para Martín Grotjahn el sentido del humor supone madurez emocional: "cuando se controlan las relaciones sociales, cuando el individuo ha logrado -o está próximo a lograr- una relación pacífica consigo mismo, sobreviene esta apreciada característica del sentido del humor (...) El humor y la sonrisa (...) se perfeccionan e integran en los estadios finales del desarrollo humano". ${ }^{10}$

\footnotetext{
${ }^{9}$ Sigmund Freud, El chiste y su relación con lo inconsciente, 1952, Buenos Aires, Santiago Rueda, p. 119.

${ }^{10}$ Martín Grotjahn, La máscara burlona, 1961, Madrid, Morata, p. 70.
}

Ahora habría que pasar a valorar tres aspectos que me parecen muy importantes: quién y qué es esa persona singular, excepcional, poseedora de sentido del humor; por qué siente y nos hace sentir a nosotros (en términos literarios ya) el freudiano 'placer humorístico'; y finalmente diferenciar el significado de algunas palabras del vocabulario humorístico, que con frecuencia se confunden: humorismo, chiste, comedia; o humorista, chistoso y cómico, entre otras.

Según su calidad y su intencionalidad el humor da lugar a varios compuestos humorísticos que oscilan entre el sarcasmo cruel o el chiste burlón y el humorismo, en cuanto éste esboza una filosofía.

Nos pueden atraer múltiples aspectos en un escritor humorístico: forma, ritmo, estilo, gracia, etc., los cuales pueden contribuir a su disfrute antes de que se desvele el verdadero 'mensaje'; o la pura delectación estética que nos transmite el autor al final. Naturalmente, a veces el escritor crea su estilo dentro del humor hasta con la ayuda del disparate (Ramón Gómez de la Serna), pero, salvo casos excepcionales, el auténtico humorista puede no recurrir siquiera al contraste o a la comparación, y su prosa, simple y llana, narra el hecho tal cual ha sucedido, o la idea, pero con tal dosis de 'gracia', 
NOTAS

'chispa', 'vena' - o como se le quiera llamar- que genera humor.

Sin embargo puede haber confusiones, por eso debe recordarse que existe, dentro del humor, lo que Hoffding llama der grosse humor, es decir, el Humorismo. Y por otro lado está el chiste, la burla, lo cómico, que sería 'el pequeño humor' o humoricidad.

El humorista -no el humoricistaes evidentemente crítico, crítico de la Vida (con mayúscula), pero también artista, y este artista no es humorista por casualidad. Cuando el humorista escribe una obra es perfectamente consciente del ángulo desde el que trata el tema. El humorista, en cuanto artista, nace con ese don; en cuanto estrictamente escritor, se hace, se pule, e igualmente 'hace' su actitud. Se trata de dos categorías bien distintas entre sí aunque necesariamente tengan que complementarse y completarse. El don, la 'vena' del verdadero humorista, viene a ser ese ‘algo' que impregna y se extiende por toda la obra, diga ésta lo que diga; lo sentimos apenas comenzamos la lectura.

El humorista, así, será tanto más estimado cuanto más sublime sea ese don, es como el poeta, a quien se le perdona un error de forma pero no de inspiración. Al humorista tampoco puede perdonársele la falta de esa 'vena'. De otro modo el humorista deja de serlo y se convierte en un contador de chistes. Pero la actitud vital, filosófica o estética, se adquiere, viene de afuera, se asimila y se hace doctrina. Por eso decimos que el humor es una actitud estética de ciertos escritores ante la vida.

Jorge Ibargüengoitia se cansó de declarar en múltiples ocasiones que no era humorista, que a él no le interesaba hacer reír a la gente.

No soy una persona que esté tratando de hacer un chiste, lo que pasa es que yo veo las cosas así. Mi vida está vista a través de algo que es una pantalla irónica. Entonces no tengo que hacer ningún esfuerzo, ni se trata de ninguna elaboración, es totalmente la expresión más directa que yo podría tener. Es decir, que si algo sale chistoso es porque está visto desde un punto de vista cómico (humorista diríamos nosotros). Nada más es mi punto de vista, no la preparación. ${ }^{11}$

Así es, Ibargüengoitia no es el cómico que cuenta chistes para hace reír, es en cambio, un escritor con sentido del humor, tiene ese 'don', esa cualidad de la que hablábamos líneas atrás; y al escribir un cuento o una novela lo emplea, expresa ese

${ }^{11}$ Fernando Díez de Urdanivia, "El escritor y su mundo", Entrevista a J.I., El Día, agosto 7 de 1977. 
humor que lo convierte en humorista (no en cómico, no en humoricista) y no por mera casualidad, sino por su visión -perspectiva-, por la actitud que tiene ante la vida o la realidad.

Aunque tenía su propia terminología, siento que Ibargüengoitia conocía perfectamente la diferencia respecto a los distintos conceptos que encierra el humor, que la gente confunde totalmente. De ahí que enfatizara tanto su posición, para que no se le 'etiquetara' como cómico o contador de chistes. Aclara lo anterior su propia distinción con relación a la intención de hacer reír y a los hechos que hacen reír:

Bernard Shaw, que en cierto sentido tenía el mismo problema que yo, decía que a él no le interesaba que la gente se riera, establecía una diferencia entre lo cómico y lo comédico, es decir, lo propio de la comedia. Lo cómico lo identificaba con su padre, decía: mi padre cuando llegaba borracho era muy cómico, era chistoso. ¿Por qué? Porque se le caía el sombrero, se rodaba las escaleras, bueno, le pasaban mil cosas que son ridículas y chistosas, pero lo que a él le interesaba era lo comédico, es decir, un señor que estando borracho y teniendo dificultad para caminar, pretende hacerse pasar como perfectamente sobrio. Esta imagen que el borracho quiere dar es la que a Shaw le interesaba: una situación interior, humana, que es muy interesante y chistosa, pero no terriblemente chistosa. ¡Vaya! No es una cosa que acabe a pastelazos. $^{12}$

Como se puede ver, el problema radica en gran parte en la falta de precisión en los conceptos. Ibargüengoitia sabía que existen diferencias, categorías; la terminología podrá variar en cada caso, pero hay distinciones. A lo que Shaw llama 'lo cómico', nosotros llamamos 'humoricidad' (humor chistoso, jocoso, intrascendente); y a lo que designa con el nombre de 'comédico', nosotros llamaríamos 'humorismo’ (actitud humorista, reflexiva, profunda, intelectualización del humor).

En otra entrevista, sí se reconoce humorista (creo que es la única ocasión en que lo admite) pero aclara: "Creo que mi humorismo me da oportunidad de ver con claridad las cosas. Ahora bien, pienso que la diferencia entre un humorista y un escritor de humor -otra vez la confusión terminológica- está en que mientras aquél busca un efecto chistoso, éste escribe sin que le importe el efecto.

12 René Delgado, “Los historiadores echan a perder la historia”, Entrevista a J.I., Plural, $\mathrm{n}^{\circ}$ 59, julio de 1978. 
NOTAS

Yo escribo las cosas como las veo у уа." 13

Que Jorge Ibargüengoitia es un escritor humorista creo que queda bien claro, no en el sentido de contador de chistes -reitero- sino en cuanto que tiene sentido del humor y lo emplea al escribir. Ahora bien, hemos señalado que existen diferentes categorías dentro del humor, ¿̇a cuál pertenece la literatura del guanajuatense?

Todos sabemos que a un escritor no se le puede encasillar o etiquetar dentro de un género o corriente literaria, pero en cambio sí se pueden advertir ciertas tendencias o características generales que enmarcan su obra. En el caso de Ibargüengoitia, nos atrevemos a calificar su humorismo como un humor realista, práctico. Es decir, no es un humorismo puro, filosófico o sublime, pero tampoco está en el extremo opuesto, el chiste. Es más bien un punto intermedio entre ambos, un puente.

Su humorismo se caracteriza por la intuición, la convicción escéptica de la vida, el perspectivismo y ese triple desdoblamiento: subjetivaciónobjetivación-reobjetivación, tan importante en el escritor humorista. Asimismo, recurre constantemente

${ }^{13}$ Guillermo Ochoa, "La beca que permitirá a un escritor escribir”, Excélsior, agosto 14 de 1969. al eterno juego ‘desmitificación-mitificación’, que abarca la Gran historia (Los relámpagos de agosto, Maten al león, Los pasos de López), o la pequeña historia (La Ley de Herodes, Estas ruinas que ves, Las muertas, Dos crímenes). Emplea la crítica y la reflexión profunda como ingredientes básicos; a veces se vale de la parodia y la caricatura, pero no como método, y siempre emplea la ironía. Por otra parte, la espontaneidad, la naturalidad son los factores fundamentales de su estilo. Todo esto pues nos lleva a darle el calificativo de humorista realista.

Las novelas de Ibargüengoitia son una expresión humorística total, desde su actitud inicial anímica como escritor -aunque él lo haya negado tantas veces- hasta la alegría formal de su estilo. Bajo esta perspectiva, es decir, con esta actitud, Ibargüengoitia pretende descubrir una realidad; en ocasiones una realidad muy personal, la suya; y en otros casos la realidad pretérita, basada en datos tomados de la historia de México o de nuestra sociedad. En el fondo todo se reduce a lo mismo: es un intento de interpretar la realidad según él la ve. Se trata en definitiva de un tipo de humorismo 'único' en la novela contemporánea mexicana, que no por su tono tan singular se aparta de la realidad. 
Sin duda, para la seriedad que durante siglos ha caracterizado a la literatura nacional, la fresca prosa de Ibargüengoitia ha seducido a todos los lectores y a los más exigentes críticos. Sólo un genio profundamente objetivo, perspicaz y minucioso como el suyo, es capaz de 'salirse de sí mismo' para observar, con ojos diferentes, dispuestos a la reflexión serena lo mismo que los demás miran con amarga preocupación.

El juego del mundo, el desilusionante y a la vez divertido juego del mundo, Jorge Ibargüengoitia lo ve con una mirada tranquila pero que tiene 'Luz de filo de cuchillo'. Humor seco, ha dicho Octavio Paz: humor de ascendencia sajona más que latina, y una cierta inclinación a difamar la realidad. Sí, pero, al mismo tiempo, cierta apacible fascinación por ese juego: juego del mundo, juego de los seres y de las cosas y de la Gran historia y la pequeña historia. Es sí un empequeñecedor de enormidades, un trivializador de trascendencias, cuyo método consiste en cotidianizar la Historia, desperdigando en anécdotas caseras lo trascendente... ${ }^{14}$

Jorge Ibargüengoitia es a mi juicio, el único escritor verdaderamente humorista de la literatura mexicana contemporánea. Su humorismo desenmascara y desnuda, pero sin odio, sin rencor. Emplea la crítica y la ironía como ingredientes básicos, sin embargo, predomina en él su espíritu lúdico. Por partes su humorismo supera la fácil barrera social y el divertimento literario.

Ibargüengoitia no es precisamente un humorista negro, es un escritor que no emite juicios ni pretende dar lecciones de moral, simplemente interpreta la realidad según la ve. Su humorismo, pues, pertenece a la vertiente realista, que no es humorismo puro, filosófico o sublime, pero tampoco está en el extremo opuesto -la comicidad- sin duda, un humorista desmitificador, que gran falta nos hace en estos tiempos tan nebulosos y sombríos.

${ }^{14}$ José de la Colina, "Jorge Ibargüengoitia (1928-1983)”, El Semanario Cultural, Novedades, diciembre 4 de 1983. 